\title{
Condiciones culturales en la constitución de identidades políticas en el Chile actual. Algunas reflexiones a partir del caso del movimiento estudiantil secundario de 2006
}

\author{
Naim Bro Khomasi \\ Universidad de Chile, Santiago, Chile. Email: naim.bro@ug.uchile.com
}

\begin{abstract}
Resumen: En base a una investigación empírica del Movimiento de Estudiantes Secundarios de 2006, este artículo desarrolla algunas consecuencias teóricas que apuntan a explorar en los aspectos culturales que condicionan la constitución de identidades políticas en el Chile actual. En un nivel de mayor abstracción, se plantea la existencia de cuatro transformaciones socioculturales propias de nuestros tiempos, que cambian radicalmente la perspectiva de creación de identidades políticas como se entendieron en el pasado. Ellas son: la reducción de espacios de formación de postura frente a los temas públicos; la ampliación valorativa de la potestad individual en la elección de pertenencias políticas; la erosión de los mapas que permiten hacer sentido del contexto societal y sus procesos de cambio; y la autonomización de la subjetividad.
\end{abstract}

Palabras clave: movimiento estudiantil secundario, identidades políticas, subjetividad.

\section{Cultural conditions in the constitution of political identities in Chile today. Some thoughts brought up by the case of secondary student's movement of 2006}

Abstract: Based on an empirical investigation of Secondary Student's Movement of 2006, this paper develops some theoretical consequences that point out to explore the cultural aspects that influence the formation of political identities in Chile today. In a more abstract level, the existence of four cultural transformations of our own times is propossed, which radically change the perspective of the creation of political identities as understood in the past. They are: the reduction of spaces for building a personal position towards public issues, the broadening valuation of individual choice of political affiliation, the erosion of the maps that contribute to make sense of societal context and change processes; and the autonomization of subjectivity.

Key words: secondary student movement, identity politics, subjectivity. 


\section{Condições culturais na constituição das identidades políticas no Chile de hoje. Algumas reflexões a partir do caso do movimento estudantil secundário de 2006}

Resumo: Com base em uma investigação empírica do Movimento Estudantes do Secundário de 2006, este trabalho desenvolve algumas implicações teóricas que apontam para explorar os aspectos culturais que influenciam a formação das identidades políticas no Chile de hoje. Em um nível mais abstrato, presenta-se a existência de quatro transformações culturais do nosso tempo, que mudam radicalmente a perspectiva da criação de identidades políticas como é entendido no passado. Eles são: a redução da postura espaços de formação sobre questões públicas, a valorização do poder alargar a escolha individual de filiação partidária, a erosão dos mapas que podem dar sentido ao contexto social; e os processos de mudança e a autonomia da subjetividade. a subjetividade.

Palavras-chave: Movimento estudantil secundário, a política de identidade,

\section{Introducción}

Nos preguntamos en este artículo por las condiciones sociales y culturales en las que se construye identidad política en el Chile de hoy, en un tiempo en el que la política no parece cumplir el rol aglutinante de la acción colectiva que tuvo tradicionalmente (Garretón, 2000). Para ello tomamos el caso del movimiento de estudiantes secundarios de $2006^{1}$-también conocido como Movimiento "Pingüino"-, el cual representa la ola de movilizaciones de mayor importancia en Chile desde la vuelta a la democracia, y expresa formas políticas propias de una generación socializada en el período de postdictadura (Gómez, 2006). Con ello, exploramos en las nuevas fronteras políticas en el Chile actual, y en los procesos culturales por los cuales se generan o, por el contrario, se erosionan las comunidades políticas.

Si recordamos, el movimiento secundario se hizo manifiesto a la luz pública en mayo de 2006, con el propósito inicial de demandar al Estado gratuidad en el pase escolar y una serie de beneficios de corto alcance, pero derivó al poco tiempo en el cuestionamiento de la Ley Orgánica Constitucional de Educación (LOCE) y otras normativas básicas del modelo de desarrollo chileno (Garretón, 2006; Ruiz, 2007). Devino, finalmente, en junio del mismo año, en la creación por parte del Gobierno del Consejo Asesor para la Calidad de la Educación, organismo pretendido para revisar la institucionalidad educativa en el país. El año anterior, sin embargo, en 2005, el movimiento secundario ya tomaba su forma definitiva, cuando el Ministerio de Educación convocó a inicios de ese año a representantes estudiantiles tanto formales (Centros de Alumnos) como no formales (colectivos con amplia representatividad) a generar propuestas para mejorar la educación. En ese trabajo de un año de duración, los estudiantes elabora- 
ron un importante documento que sirvió de base para la formulación de demandas el año posterior.

La formación y despliegue de este movimiento poseen peculiaridades cuyo estudio puede contribuir a comprender los procesos de constitución y transformación de la acción colectiva en las sociedades actuales. Entre estas particularidades (Garretón, 2006; Ruiz, 2007; González, Cornejo, Sánchez y Caldichoury, 2007) están su capacidad de levantar demandas de carácter estructural, al hacer evidente la crisis de la educación como mecanismo de ascenso social, recibiendo así el apoyo de grandes segmentos de la población y encauzando a otros actores colectivos en torno a su propio proyecto. Además, fueron novedosas sus formas de organización, caracterizadas por ser autónomas del sistema de partidos; poseer líderes revocables provenientes de afiliaciones políticas tradicionalmente opuestas; y por la horizontalidad de sus modos de participación, prevaleciendo en él los mecanismos de decisión de tipo asamblea.

\section{La ausencia de banderas unificadoras}

Desde nuestro punto de vista, no existen símbolos políticoidentitarios unificadores de orden ideológico que permitan hablar de la creación de una nueva identidad política en el movimiento estudiantil en su conjunto. Ello no significa que no existan transformaciones político-culturales expresadas en el movimiento; las hay, sin duda, pero no se traducen en una cristalización suficientemente explícita de significados políticos aglutinantes que den lugar al surgimiento de una nueva identidad política.

Vale decir, en este sentido, que cultura política e identidad política son conceptos distinguibles y fenómenos que, en la práctica, bien pueden operar según dinámicas diferenciadas e incluso contrapuestas, como sugerimos para el caso en cuestión. Identidad política, siguiendo la definición de Hakan Yavuz (2003), es el proceso por el cual se llega a ser consciente de los marcos de referencia según los cuales se actúa, utilizando tales marcos como un horizonte de sentido explícito en la acción política, y afirmando en dicho proceso la unidad y solidaridad colectiva, por medio de un doble proceso de diferenciación frente a la alteridad (el enemigo; el otro) y de homogeneización de la diversidad interna (Aboy Carlés, 2001). Ahora bien, para que los cambios culturales redunden en cambios propiamente identitarios, los nuevos elementos culturales e ideológicos deben ser identificables por los sujetos de forma clara y deben tener una referencia explícita al "nosotros", proceso en el cual es de especial importancia la existencia de una unidad de nominación (Aboy Carlés, 2001) -esto es, un nombre-, que permita que se indique la identidad política, facilitando el manejo cognitivo y la difusión de las preguntas por el "quién es quién, quiénes son ellos y quiénes somos nosotros”. Sin embargo, la sociedad contemporánea, como veremos más adelante, comporta transformaciones culturales que, lejos de permitir la cristalización de nuevas identidades políticas, dificultan tanto el proceso de homogeneización de actores políticos 
bajo referentes explícitos, como de auto-comprensión de la posición de éstos en el marco de las fuerzas estructuradoras de la sociedad y la historia, ambos elementos capitales en la formación de comunidades políticas gregarias sedimentadas y estables en el tiempo.

En este sentido, y a modo de explicitar los fundamentos teóricometodológicos del estudio, señalamos que desde una perspectiva típicaideal, se produce transformación de identidad política en el momento en que un colectivo experimenta todas o algunas de los siguientes procesos: se aglutina bajo nuevos referentes ideológicos, culturales, sociales y organizacionales, distintos a los del pasado; en oposición a nuevos enemigos; en la perspectiva de una nueva ordenación del pasado y del futuro; y todo ello contenido bajo una nueva unidad de nominación. Esta nueva identidad debiera ir más allá de la especificidad espacio-temporal del movimiento concreto que le dio origen, existiendo en ella aspectos abstractos con la generalidad suficiente para ser utilizados por otros actores sociales, a propósito de demandas diferentes que las originales, y con la posibilidad de ser actualizados en distintos puntos del tiempo, pero conteniendo en su seno la estampa del movimiento original como un hito importante en su creación. Para el caso del movimiento secundario, planteamos la hipótesis de que dicha identidad novedosa era producto, por un lado, de la irrupción pública de una transición política-cultural de larga data, que subterráneamente habría tenido lugar en la generación nacida después del plebiscito de 1989 y socializada en el contexto de los gobiernos de la Concertación, y, por otro, del efecto de mecanismos conducentes al cambio identitario propios toda acción colectiva (McAdam, Tarrow, \& Tilly, 2004), pero especialmente presentes en las movilizaciones de 2006, dada su composición social y política heterogénea, y su impronta generacional particular.

Lo ausencia de lo anterior nos lleva a plantear que el cambio identitario en el movimiento estudiantil debe ser analizado en términos de la variable que Charles Tilly (2004) denomina “activación /desactivación”, aludiendo al grado en que una identidad adquiere menor o mayor poder organizador sobre las relaciones sociales en un contexto determinado, sin por ello resignificar sus contenidos ni transformar los actores colectivos que articula, como sugieren las otras formas que el autor define puede tomar el cambio identitario ${ }^{2}$. En este sentido, las identidades que organizan tradicionalmente la vida política en Chile no son explícitamente impugnadas o reemplazadas en el movimiento de estudiantes de 2006, ni tampoco son transformados los actores que las abanderan, no obstante, parecen haber perdido la capacidad de organizar con la fuerza con que lo hacían en el pasado las relaciones sociales en el marco de la acción colectiva. En el nivel ideológico, el movimiento estudiantil abanderó una serie de demandas que generaron consenso en una gama muy amplia de sectores históricamente contrapuestos y otros sin identidad política definida, pero ello no condujo a una síntesis que marcara el nacimiento de una nueva identidad política. Por ello, el movimiento estudiantil, no produce ni reproduce identidad política, pues, si bien expresa elementos ideológicos nuevos, no produce ni reproduce con ellos una arquitectura ideológica ni una nueva uni- 
dad de nominación con la abstracción suficiente para ser utilizada por otros actores colectivos en un contexto espacio-temporal diferente y con el nivel de concreción suficiente para provocar un sentido de pertenencia. Pero, ¿por qué se produce este divorcio entre acción colectiva e identidad política en el mayor movimiento social de los últimos 20 años, siendo su carácter fundamentalmente político?

Según nuestro análisis, los elementos al mismo tiempo empíricos y teóricos que permiten explicar tal fenómeno son cuatro: 1) la capacidad relativizante sobre las divisiones ideológicas de dicotomías estructurantes que se derivan del distanciamiento entre sociedad y política; 2) la erosión de los mapas cognitivos por los cuales se entiende tradicionalmente la política en Chile; 3) la ampliación valorativa de la potestad del individuo de crear ideas y pertenencias propias, y el consecuente debilitamiento de las constricciones colectivas; y 4) la autonomización de la subjetividad frente a la política. Todas ellas, en definitiva, fueron las que permitieron la convivencia de identidades políticas históricamente contrapuestas en un único movimiento social, sin la necesidad de sintetizar algo nuevo a partir de ello. Tienen su origen en procesos societales ampliamente estudiados, cuyos caracteres por ningún motivo han sido descubiertos aquí, pero que hemos sabido vincular por medio de contrastación empírica con el fenómeno de la identidad política en el movimiento secundario. Veamos ahora de qué se tratan los cuatro puntos.

\section{Espacios sociopolíticos de toma de postura}

"Diferente a las anteriores polarizaciones ideológicas, hoy en día resalta la distancia entre gobernados y gobernantes.

Las identidades colectivas pierden aquella consistencia que facilitaba a la gente medir las cercanías y distancias de su pertenencia, al mismo tiempo que ganan preeminencia nuevos mecanismos de mediación -la televisión- que generan una cohesión rápida, pero volátil.”

(Lechner, 2002, pág. 33)

Identidad política no es una categoría ahistórica aplicable a toda época, sino que es específicamente moderna. Tiene su origen en las revoluciones de fines del siglo XVIII, especialmente la francesa (Ghiretti, 2007), cuando la dicotomía gobernante/gobernado propia del ancien régime, da paso a un modelo político en el cual el conflicto es endógeno al sistema y las personas toman postura frente a la forma de gobierno y conducción general de la sociedad. Las identidades políticas, por lo tanto, toman forma en el espacio político-estatal, siendo la relación Estado y sociedad propiamente moderna su determinante estructural y condición de existencia. Del mismo modo, en el caso chileno, los espacios donde tradicionalmente se construyeron las identidades políticas fueron aquellos existentes en torno a los partidos políticos, al Estado, y a las asociaciones de la sociedad civil 
constituida en referencia a los dos anteriores. Allí se crearon las condiciones organizacionales que permitían la existencia de comunidades de discusión (Baño, 2010) y el consecuente procesamiento cognitivo y relacional de la definición del “nosotros” y del “ellos” y, luego, la creación de solidaridades estables en el tiempo.

Sin embargo, la represión política y las reformas estructurales de los años 70' y 80' cambiaron esta situación. Allí tomó forma un nuevo tipo de relación entre Estado y sociedad que desarticuló el sistema político y la sociedad civil constituida en referencia al Estado, el cual pasó a ser un agente de la competitividad nacional en el nuevo contexto de globalización económica y financiera (Castells, 2005). En este tipo de relación entre Estado y sociedad cobra nueva vida la dicotomía gobernantes/gobernados, pero esta vez no como la opresión de un orden que parece divinamente ordenado, sino uno que opera en función de fuerzas globales autónomas y naturalizadas, que poco tienen que ver con la voluntad general de la nación. Tal condición estructural constriñe los espacios donde operan los mecanismos de formación de identidad política por los cuales los sujetos se posicionan ante la realidad social y construyen solidaridades estables en el tiempo. De ahí que la señalada dificultad del movimiento "pingüino" de generar una identidad colectiva de carácter político sea consecuencia directa del distanciamiento entre Estado y sociedad, y más específicamente, de la pérdida de los espacios sociopolíticos donde los sujetos tradicionalmente construyeron sus posturas en relación a los temas públicos.

Así, cuando en Chile la actividad política se profesionaliza y se distancia de la sociedad, las identidades políticas sufren una constricción que no es sucedida necesariamente por una resignificación de las mismas, produciendo que nuevas dicotomías "externas” cobren fuerza en la esfera política. Estas dicotomías externas tienen el poder de relativizar el poder organizador de las propiamente ideológicas -esto es, relacionadas a proyectos de sociedad-, produciendo que el "enemigo" y el "nosotros" constituyentes del movimiento social ya no sean definidos ideológicamente. Denominamos el primer tipo de dicotomías “de contenido" y las segundas "de forma”, refiriendo aquéllas a las ideas sobre el tipo de sociedad que se quiere construir, y estas a las formas por las cuales se gestionan tales ideas.

Proponemos que las dicotomías que atraviesan al movimiento estudiantil y le permiten obviar las divisiones tradicionales, dándole unidad interna y un nuevo modo de definir al enemigo, tienen mucho que ver con la forma de hacer política y menos que en el pasado con el contenido. El análisis empírico de los discursos de los participantes del movimiento arroja que las principales dicotomías de este tipo son las siguientes: discurso/ práctica y oportunismo/sinceridad. En este sentido, los estudiantes representan como enemigo al gobierno de la Concertación ${ }^{3}$ no por su color político -recordemos que algunos de los voceros se identificaban con esta coalición-, sino, primero, por las promesas incumplidas de la transición y, segundo, por la distancia que expresa entre discurso y acción. Según este principio de crítica, la distinción izquierda/derecha, y especialmente la de 
dictadura/democracia, no desaparecen ni se resignifican, pero pierden capacidad de organiza las relaciones al interior del movimiento, cuando los estudiantes caen en cuenta que los sectores nominalmente de derecha al interior del movimiento no son en realidad un bloque ideológico, y cuando se constata que independiente del color político, existe una comunidad de personas que en la práctica -y no en el discurso- están comprometidos con luchar y mejorar la educación y la sociedad. En este sentido, el movimiento estudiantil de 2006 no fue en su fundamento una asociación entre distintos bloques políticos fuertemente constituidos ideológicamente, sino que una unidad que, entre muchos otros ejes de división, contuvo una diversidad política inusitada.

Las mencionadas dicotomías estructurantes externas, sin embargo, no han adquirido en los estudiantes el grado de explicitación suficiente para configurar una identidad política que organice solidaridades estables en el tiempo en función de superar las contradicciones que sus pares de opuestos sugieren. Ello no significa que lo político -esto es, la búsqueda de la buena sociedad- no sea importante para los miembros del movimiento; por cierto que lo es, pero cuando los espacios culturales e institucionales en los cuales se despliega lo político son escasos, es difícil la creación de identidades políticas estables en el tiempo, pues ellas precisan de una organización cognitiva que explícitamente otorgue sentido a la acción.

La analogía con el fútbol es iluminadora para entender lo que ha pasado en política en Chile en las últimas décadas. Siendo los políticos los equipos de fútbol y la sociedad los hinchas, el cambio substancial que ha ocurrido en Chile es el cierre de los estadios y la transmisión de los partidos únicamente a través de la televisión, convirtiéndolos a éstos en espectadores. Ello supone un impacto radical para las identidades en el fútbol, puesto que el estadio es el espacio donde ellas adquieren su pleno sentido colectivo y fuerza expresiva; donde se hace evidente y se simboliza la multitud que representan el "nosotros", y, a su vez, el “otro". En el estadio de fútbol, podemos decir con certeza, hay un principio que organiza las relaciones sociales, tanto de los jugadores como los hinchas: la identificación de equipo. Pero cuando se cierran los estadios y se transmiten los partidos sólo por televisión, la distinción futbolística “nosotros”/”ellos” pierde fuerza frente a otras distinciones, y finalmente se desactiva (aunque no sea transformada). Las personas siguen adscribiendo a un equipo de fútbol, pero sus sentidos de identificación se tornan cada vez más abstractos y dejan de constituir el principio más importante de organización de las interacciones al interior de la sociedad. En adelante, lo que queda por hacer es reconstruir el espacio donde la identidad futbolística cobra vida: el estadio, y ello bien puede convertirse en un aglutinante para la acción colectiva.

\section{Individualización}

La pérdida de los espacios sociopolíticos de construcción de identidades políticas está acompañada de otros procesos de tipo cultural, en 
especial los fenómenos de individualización, erosión de los mapas cognitivos, y autonomización de la subjetividad frente a las divisiones políticas tradicionales. La individualización corresponde al proceso por el cual el individuo se transforman en "actor, constructor, malabarista y director de escena de su biografía, su identidad, sus redes sociales, sus ligazones y convicciones” (Beck, 1998, pág. 131), recayendo en él la responsabilidad exclusiva de producir su propia vida. En dicho proceso pierden peso las fuentes de identificación colectivas, y particularmente los roles y categorías que imponían los modos políticos propios de la sociedad industrial, los cuales, según Giddens (1991), se caracterizan por el gran poder organizador de los ejes público/privado e izquierda/derecha. Es así que la individualización relativiza la perspectiva centrada en las clases sociales y colectividades políticas, según la cual los individuos se relacionan con la sociedad en tanto miembros del grupo, o lo que Garretón denomina “descategorialización”, es decir, la pérdida de saliencia o “borroneo” de las fronteras sociales en referencia a las cuales los individuos se relacionaban con los demás miembros de la sociedad.

Este principio en el movimiento “pingüino” se manifiesta de formas muy específicas y empíricas. En primer lugar, cobran mucha importancia los valores de respeto a la diversidad de opiniones y posiciones políticas. Una entrevistada, en este sentido, recordaba a un filósofo que señalaba que quizás podía no opinar lo mismo que el otro, pero que daría la vida para que ese otro pudiera expresar su opinión. Por otro lado, el principio de individualización se expresa en la impugnación explícita por parte de algunos sectores al carácter uniformizante de la pertenencia a partidos políticos. “¿Dónde queda la política del individuo?”, se preguntaba un entrevistado, señalando que, no obstante la adherencia de un grupo a un determinado partido político único, no todos ellos piensan igual. Y más aun, el mismo sujeto iguala la pertenencia a partidos políticos a la uniformización de las religiones:

(...) las banderas políticas son como las religiones, como que abarcan a una cachada ${ }^{4}$ de gente, pero ¿dónde queda el individuo? ¿Dónde queda la política del individuo? ¿Dónde queda la fe del individuo? no toda la gente de una misma religión cree en lo mismo.

Otros aspectos en los cuales se expresa la individualización es en el esfuerzo consciente de muchos participantes de forjar una posición propia frente a los asuntos sociales que les inquietan, independiente de las categorías ideológicas que ahora pasan a ser "principios tentativos y parciales orientados hacia formas de vida más humanas” (Garretón, 2000). También son expresivas las imágenes de la sociedad que expresan los consultados acerca de la revolución que muchos pensaron estar efectuando, aludiendo a una sociedad libre, en que todos pudieran tomar decisiones sin pasar a llevarse los unos a los otros. Además, el sentido que atribuyen a su lucha por la educación, tiene mucho que ver con la posibilidad de que ésta sea un elemento que les dé las herramientas para construir la vida que ellos quieren para sí, principio clásicamente individualizado, puesto que desde esta 
perspectiva, la sociedad, y en particular la educación, son un recurso en la construcción de las biografías personales, y en tanto tal, un motivo de lucha. Finalmente, la individualización se manifiesta en la crítica explícita al gobierno por jugar con las formas de vida de los estudiantes, sin hacerles partícipes de la construcción de sociedad, la cual reconocen como el contexto en el cual deben tomar sus decisiones de vida.

La presencia del principio fuerte de individualización conduce a una paradoja, relacionada con que la reconstitución de los espacios donde se construyen posturas frente a la realidad política -tema abordado anteriormente--, es condición necesaria, pero no suficiente, para la producción o reproducción de identidades políticas en el sentido en que lo propone Aboy Carlés (2005), de homogeneización de la diversidad interna a la par que diferenciación externa. Ello porque la valoración de la potestad individual de elegir pertenencias ideológicas, o no, y la consecuente pérdida de capacidad de presión del colectivo, permiten al sujeto generar posturas políticas sin "amarrarse” a una categoría colectiva; y si lo hace en un determinado momento, sin la obligación de permanecer allí cuando su posicionamiento personal frente a los mismos temas o las circunstancias de su afiliación hubieran cambiado. De acuerdo al fenómeno de la individualización, cuando generalizado a nivel societal, el individuo se transforma en el arquitecto de su propia ideología y pertenencias colectivas, por lo que puede traspasar fácilmente las distintas divisiones tradicionales que existen entre ideologías e identidades políticas, tomando lo que necesita para formar su postura propia desde lugares muy disímiles. Así, la pregunta política que surge de esta situación es cómo se construyen identidades políticas y sujetos colectivos con capacidad de crear una sociedad que gobierna su propio destino, en un contexto cultural individualizado. En consonancia con el Informe de Desarrollo Humano del 2002 (PNUD, 2002) señalamos que la individualización no impide la existencia de una ciudadanía con toma de posición e interesada en los asuntos políticos, pero ¿permite la creación de identidades políticas propiamente tal, es decir, la existencia de un "nosotros” político fuerte, solidario y estable en el tiempo?

\section{Erosión de los marcos cognitivos}

Otro fenómeno que relativiza el poder organizador de los clivajes políticos tradicionales en el movimiento estudiantil, es la erosión de los mapas cognitivos (Lechner, 2002) que ordenan las representaciones acerca de la sociedad, sus conflictos y sus procesos de cambio. Ello dice relación con que el mundo actual es complejo y es difícil para los sujetos hacer sentido de él en forma clara y consensuada. No se trata tanto de que la gente hoy piense diferente que en el pasado -aunque que también sea así-, sino que ya no sabe muy bien qué pensar en lo que respecta a los niveles más abstractos de la vida social y al sentido de la historia. Los enunciados sobre la realidad que abanderan las ideologías tradicionales no le son tan evidentes, y sin embargo no son capaces de sostener su contrario más que en aspectos muy específicos y parciales, lo cual comporta un gran impacto 
sobre las identidades políticas, dado el origen histórico común que poseen identidad e ideología (Ghiretti, 2007).

Según Norbert Lechner (2002) la erosión de los mapas cognitivos con los cuales se piensa la vida en sociedad y se vincula la identidad colectiva con una tradición común y un proyecto de futuro, es uno de los principales procesos en la definición actual de lo político, al desfigurarse un conjunto de ejes clasificatorios que permitían a las personas interpretar las distintas opciones en juego en el campo político. Los chilenos, señala Lechner, experimentan una dificultad creciente de hacer sentido de las posiciones y distancias existentes en el orden político; hacer sentido de las transformaciones en curso y entenderlas desde una perspectiva de pasado y futuro; y, en consecuencia, tomar posición frente a un orden social que les parece cada vez más ajeno y lejano, con el cual no pueden sentirse identificados ni vincularse afectivamente. Se produce, así, una incongruencia entre las formas tradicionales de pensar la política y su forma cotidiana de operar, generando malestar en la sociedad. No es un tema de verdad o falsedad, sino que de categorías culturales que hacen sentido del contexto social y sus procesos de cambio, permitiendo la existencia de lineamientos conducentes a la acción en la esfera individual y colectiva. Tampoco es un problema específico de los estudiantes, sino que de una sociedad que no logra formular una representación clara acerca de sí misma, pues, como señalara Lechner (2002, pág. 28), la erosión de los mapas mentales provoca que "los conflictos existentes ya no permiten estructurar identidades colectivas y ordenar las opciones en juego".

En el movimiento estudiantil este fenómeno se pone de manifiesto en la carencia de un proyecto claro de sociedad y en la dificultad por parte de los participantes de describir su domicilio político. Los sujetos, claramente, emprenden esfuerzos cognitivos por producir lineamientos en esta materia, y ciertamente el espacio del movimiento representó una intensificación de tales esfuerzos, pero las categorías de compresión de la sociedad no fueron para ellos una ideología previamente dada, la cual simplemente tuvieron que aplicar a su situación concreta, sino que fue materia de construcción propia. Allí radica una de las principales diferencias del movimiento secundario de 2006 con los movimientos estudiantiles del los años 60’.

No obstante, adoptamos aquí la propuesta de Eyerman y Jamison (1991), que señalan que, justamente, los movimientos sociales conforman los espacios donde se originan muchas de las ideas acerca de la sociedad. Su concepto de movimiento social va en línea con tal enfoque, siendo el sello distintivo de éstos la existencia de un "territorio cognitivo", o "espacio conceptual”, en torno al cual se produce pugnas entre actores y organizaciones, orientadas a reafirmar o transformar los significantes en torno a un determinado asunto. Tal proceso, lo denominan "praxis cognitiva", correspondiente a la actividad concreta por la cual actores colectivos e individuales generan y difunden nuevo conocimiento, refirmando o transformando las distinciones y significantes sociales en torno a una determinada pro- 
blemática. Es esta práctica cognitiva la que define a un movimiento social y le otorga su identidad. Dicho esto, vale señalar que el movimiento "pingüino" fue relativamente corto en duración y por las características propias de un movimiento de estudiantes secundarios -que debe ser constantemente regenerado por la constante salida de los dirigentes una vez que concluyen enseñanza media-, no tuvo el espacio de tiempo suficiente para sedimentar nuevas categorías de interpretación de la sociedad y sus procesos de cambio, y en base a ello, una nueva identidad. No obstante, de continuar "subterráneamente" o de forma manifiesta, es cierta la posibilidad de que tales procesos de elaboración conceptual e ideológica estén teniendo lugar, produciendo un acervo cultural latente al que futuros actores sociales podrán recurrir.

\section{Autonomización de la subjetividad}

Estrechamente vinculado con el proceso de individualización, la expansión valorativa y autonomización de la subjetividad como principio de interacción social es el cuarto fenómeno que relativiza la capacidad divisoria de las identidades políticas tradicionales en el contexto del movimiento de estudiantes secundarios de 2006. En este sentido, es posible afirmar que la significancia del episodio de movilizaciones para los participantes, junto con ser un espacio de formación política, fue la experiencia de vida comunitaria fuertemente afectiva. En ello no habría novedad respecto de la acción colectiva tradicional, si no fuera por la autonomía que expresó dicho principio afectivo frente a las divisiones ideológicas tradicionales, en dos sentidos principales, en término de estructuración de redes sociales, y de los objetivos filosóficos e ideológicos últimos de la lucha.

Por un lado, se tiene que cuando los estudiantes reivindican tan fuertemente la autonomía de las relaciones de fraternidad frente a los dictados de la división política e ideológica que "impone” la sociedad, las redes de sociabilidad dejan de canalizarse según tales divisiones, estructurando un modo de asociatividad entre los estudiantes que impide la formación de cliques ideológicos cerrados en sí mismos -con las derivas cognitivas e ideológicas que ello implica-. Con ello, se relativiza el poder organizador que pudieran ejercer los clivajes tradicionales sobre las relaciones sociales y las identidades, al permitir un tránsito más fluido de las personas entre diferentes grupos de pensamiento, sin que ello signifique una contradicción o sentimientos de "traición". De este modo, son cada vez menos los grupos de amigos o las parejas que, por dictado de las divisiones sociales, se conforman en el plano ideológico de modo homogéneo, y por tanto, dejan de operar principios de producción de conocimiento social según los cuales tales grupos auto refuerzan sus modos de ver el mundo en una dirección muy específica, y crecientemente distanciados de grupos de sociabilidad homogéneamente constituidos en base a otros ejes ideológicos.

Otro elemento que pone en evidencia la autonomización de la subjetividad frente a la ideología, es el valor que se asigna a la felicidad como 
el fin último de los cambios sociales por los cuales lucha el movimiento estudiantil. En este sentido, las demandas más tradicionales que el movimiento estudiantil también albergó -igualdad de oportunidades, rol del Estado en la educación- fueron resignificados en vistas de alcanzar este principio último, como expresa la siguiente cita de una vocera del movimiento estudiantil, ilustrativa del proceso cognitivo que conduce a tal resignificación:

\begin{abstract}
“(...) si tu cambias la educación (...) no siguen reproduciéndose brechas sociales. Al no reproducir brechas sociales haces que la gente de alguna u otra forma sienta ese sentimiento de tranquilidad y felicidad en el lugar que está, por ende gestionas de alguna forma de que estas personas se sientan más felices en la sociedad en la que están participando y están viviendo, por ende generai una mejor sociedad”.
\end{abstract}

La capacidad relativizante de este principio sobre las identidades políticas tradicionales se deriva del hecho de que la felicidad, al situarse en otro ámbito de la acción, es irreductible a ejes más clásicos de la lucha social. Garretón (2002) plantea que los tradicionales motivos de lucha política -la lucha por la libertad en contextos autoritarios, por la justicia social en sociedades capitalistas, y por la autonomía nacional en países dependientes-, hoy abren espacio a la emergencia de otro motivo irreductible a éstos y de naturaleza substancialmente diferente: la lucha por la felicidad y la autorrealización. Ella redefine la naturaleza de la acción política, puesto que "ni la superación de la explotación, de la opresión, ni las aspiraciones por igualdad y libertad agotan el imaginario y los sueños de la gente: además de ello quieren ser felices y no creen que la igualdad y la libertad les asegure por sí mismas esa felicidad, sino que son aspiraciones irreductibles entre sí” (Garretón, 1994, pág. 59). En otras palabras, la igualdad deja de ser un valor en sí mismo, y pasa a ser un instrumento necesario, pero no suficiente, para garantizar la felicidad de todas las personas.

La autonomización de la subjetividad frente a la ideología, está en línea con el planteamiento de Farhad Khosrokhavar (2002) quien señala que dos de las principales transformaciones de la política en la sociedad contemporánea son, por un lado, la creciente importancia política que adquieren aspectos concernientes a la vida privada que antes eran excluidos de esta esfera, y, por otro lado, la pérdida de centralidad de la política sobre la vida colectiva e individual, perdiendo así su capacidad de polarizar la sociedad y constituyéndose como una más entre otras esferas que ahora se autonomizan y adquieren consistencia propia: "Por consiguiente" -afirma Khosrokhavar (2002, pág. 21)- “asistimos a la irrupción, en el espacio público, de aspiraciones enraizadas en lo privado y que de este modo se politizan, y, en concomitancia, a la desaparición del monopolio de lo político, que hoy se presenta como uno de los momentos esenciales de la vida social, pero ya no como el único”. 


\section{Proceso cultural}

Nuestra propuesta es entender la discusión anterior desde dos perspectivas: la degenerativa y la generativa. La primera perspectiva tiene que ver con lo que ya no es; ver el movimiento estudiantil como expresión de la erosión de las formas culturales claras e inteligibles de la generación del '68 y explicar esto por el quiebre radical que significó en la sociedad chilena la experiencia dictatorial, y el advenimiento de la sociedad postindustrial, o la modernidad reflexiva, si se quiere. Ello nos permite comprender que lo que hoy parece natural, no lo es, sino que es históricamente excepcional. Desde esta perspectiva decimos que la incapacidad de los estudiantes de forjar una identidad ideológica clara; de entenderse como continuadores de una tradición de lucha social; y orientarse en dirección a un horizonte de futuro más o menos definido; es expresión de la erosión de los mapas cognitivos de la sociedad y el distanciamiento entre sociedad y Estado.

La perspectiva generativa, por su lado, mira más bien a lo que está siendo creado y se pregunta por la inserción del movimiento de estudiantes secundarios en un proceso más general de transformación cultural que tiende a la producción de formas ideológicas e identitarias relativamente estables e inteligibles, $y$, en un sentido más general, de una sociedad que se hace dueña de su propio destino. Esta perspectiva contiene una cierta teleología que asume que lo normal es la existencia de formas culturales claras y estables, y que la indefinición del presente no es más que el signo de una etapa de transición. Si bien en este trabajo no nos hacemos cargo de las consecuencias epistemológicas de esta postura, reivindicamos su capacidad de iluminar ciertos aspectos de un período histórico, orientar la investigación, y ser políticamente constructiva.

El aporte de estas notas es ayudar a entender el movimiento secundario desde la segunda perspectiva. En este sentido intentamos delinear las implicancia del movimiento, así como las condiciones culturales y estructurales allí operantes, en la perspectiva de fortalecer la sociedad civil en Chile. En esto seguimos la línea de discusión de varios autores que ven en esta problemática el principal desafío cultural del Chile actual. Entre ellos, Garretón (2000), quien señala que "El futuro de la sociedad chilena radica en su capacidad de construcción de un sistema sociopolítico que rescate la idea de una comunidad nacional que no se reduce a un mercado ni a un conjunto de instrumentos y técnicas. Lo que el país necesita”-dice- "ya no es un 'milagro económico' sino un gran salto adelante que debe ser político, institucional y cultural” (2000, págs. 185-186). Así mismo, Lechner (2002), Castells (2005), y PNUD (2000) apuntan desde sus respectivos planteamientos a esta problemática central. Desde nuestro punto de vista, la formación de identidad política es substancial para entender las derivas históricas de este proceso, pues apunta a entender la perspectiva interna de los sujetos, por la cual ellos se agrupan, crean solidaridades estables en el tiempo y vinculan una cierta imagen de sociedad al compromiso colectivo del "nosotros". Ello no significa que la acción colectiva dependa de la identidad política; son dos fenómenos que poseen dinámicas autónomas y que 
dependen de factores diferentes (Walder, 2009), sin embargo, ésta tiene la capacidad de darle a aquella coherencia en el tiempo y una dirección histórica relativamente clara e intencionada.

En lo que sigue delineamos unas breves notas acerca de las implicancias del movimiento estudiantil y de las condiciones culturales y estructurales que en él se expresan para la construcción de una sociedad fuerte y capaz de gobernar su propio destino.

\title{
Reflexiones finales: espacios para la formación de identidad
}

\author{
“al desaparecer las comunidades de discusión \\ que permitían la formación y crítica de las opiniones, \\ el ciudadano se transforma en televidente carente de filtros, \\ quedando indefenso frente a la luminosa caja cada vez más plana”
}

(Baño, 2010)

Una primera respuesta a la pregunta por los espacios en que los sujetos generan identidades políticas, es que el propio movimiento estudiantil de 2006 fue uno de esos espacios. Como señala Lechner (2002, pág. 12): "desarrollamos tal imaginario del Nosotros en la medida en que realizamos experiencias exitosas de acción colectiva”. En él operaron mecanismos conducentes a la formación de identidad política propios de todo movimiento social, que implicaron elaboración ideológica y posicionamiento frente a asuntos públicos. Desde la perspectiva de McAdam, Tarrow y Tilly (2004), cuando un actor colectivo irrumpe en el espacio público, intensifica sus esfuerzos cognitivos por responder a la pregunta por el "quién es quién” y, particularmente, por establecer la legitimidad o ilegitimidad de sí mismo y del otro. Los actores movilizados buscan reafirmar la propia identidad, intentando legitimarse públicamente y representar expresivamente la unidad interna del colectivo, activando así la doble dialéctica de identificación grupal y categorización por la cual las identidades se construyen (Jenkins, 2008). Luego, desde la perspectiva de la tradición, los movimientos sociales se convierten en parte del acervo cultural depositado en la memoria colectiva de los actores colectivos posteriores.

Esta perspectiva optimista también es planteada por Gabriel Salazar y Julio Pinto (2002), quienes señalan que el tipo de sociabilidad que caracteriza a la juventud contiene en su seno el potencial de producir sujetos colectivos. Ellos tienen el impulso a crear sus propios espacios de participación, dice los autores, lo que es "equivalente a tener el principio generador de toda ‘nueva’ sociedad” (Salazar \& Pinto, 2002, pág. 262).

Lo planteado hasta ahora nos lleva a entender dicho proceso de producción de ideología, de identidad y de regeneración de los mapas 
cognitivos, desde la perspectiva de un nuevo contexto sociocultural, diferente al del pasado, que plantea la aparente paradoja de cómo formar identidad política cuando el individuo es un sujeto individualizado y poco dispuesto a "amarrarse" a las categorías que la sociedad le impone; cuando no vivencia cotidianamente espacios en que pueda tomar postura frente a los asuntos públicos; cuando ve en la felicidad y en los vínculos sociales afectivamente gratificantes el sentido principal de su acción, teniendo capacidad variable de ligar dicho fin con las condiciones societales en que se desenvuelve; y cuando la sociedad no le ofrece categorías claras e inteligibles con las cuales interpretar la sociedad que lo rodea, y según las cuales entenderse a sí mismo en relación ella. Dado este nuevo contexto sociocultural, ¿es posible afirmar que nos encontramos ante el fin de las identidades políticas fuertes, y ante la constitución de nuevos tipos de sujetos colectivos radicalmente diferentes a los del pasado? Todo depende de la continuidad en el tiempo de la acción colectiva, que permita la existencia de espacios de procesamiento cognitivo, afectivo y asociativo de la pregunta por la sociedad, y que sepan utilizar las transformaciones culturales operantes en la sociedad en función de viejas y nuevas demandas. 
Polis, Revista de la Universidad Bolivariana, Volumen 10, $N^{\circ}$ 28, 2011

\section{Notas}

${ }^{1}$ Los elementos empíricos de la investigación consiste en 10 entrevistas semiestructuradas, aplicadas a fines del año 2009 a sujetos participantes del movimiento estudiantil de 2006, tanto líderes y voceros, como otros participantes.

${ }^{2}$ Inscripción/supresión, es decir, la formación o desaparición de fronteras sociales; transferencia de sitio, esto es, la mantención de los grupos que separa una frontera social, pero siendo resignificado uno o los dos lados; y relocalización, es decir, el cambio en la posición de una frontera, separando así actores distintos que en su ubicación anterior.

${ }^{3}$ Coalición de centro-izquierda gobernante en las décadas post-dictadura, 90’ y 00’.

${ }^{4}$ Chilenismo que significa "gran cantidad". 


\section{Bibliografía}

Aboy Carlés, G. (2005), "Identidad y diferencia política”. En F. Shuster, Tomar la palabra: estudios sobre protesta social y acción colectiva, Prometeos Libros, Buenos Aires.

Ídem (2001), Las dos fronteras de la democracia argentina: la reformulación de las identidades políticas de Alfonsín a Menem, Homo Sapiens, Buenos Aires.

Baño, R. (2010), “Ha muerto la Reina... ¿Que viva el Rey?”, Análisis del año 2009 , 7-30.

Beck, U. (1998), La invención de lo político, Fondo de Cultura Económica, Buenos Aires.

Castells, M. (2005), Globalización, desarrollo y democracia: Chile en el contexto mundial, Fondo de Cultura Económica, Santiago.

Eyerman, R., \& Jamison, A. (1991), Social Movements. A cognitive approach. University Park: Penssylvania State University Press.

Garretón, M. A. (1994), La faz sumergida del iceberg. Estudios sobre la trasformación cultural. Ediciones CESOC-LOM, Santiago.

Ídem (2000), La sociedad en que viviremos, LOM, Santiago.

Ídem (2002), "La transformación de la acción colectiva en América Latina”, Revista de la CEPAL, núm. 76.

Ídem (2006), Del postpinochetismo a la sociedad democrática. Globalización y política en el Bicentenario, Editorial Debates, Santiago.

Ghiretti, h. (2007), "Un capitulo sobre las identidades politicas modernas: la izquierda a la luz de las tesis de Carl Schmitt”, Anuario Filosófico, xl/1, 149-173.

Gómez Leyton, J. C. (2006), "La rebelión de las y los estudiantes secundarios en Chile. Protesta social y política en una sociedad neoliberal triunfante", OSAL, Observatorio Social de América Latina, año VII, no. 20 , 107-117.

González, J.; Cornejo, R.; Sánchez, R. \& Caldichoury, J. P. (2007), “Perspectivas y significados del movimiento nacional de estudiantes secundarios”, OPECH, Universidad de Chile.

Jenkins, R. (2008), Social identity, Routledge. Oxon. 
Polis, Revista de la Universidad Bolivariana, Volumen 10, $N^{\circ} 28,2011$

Lechner, N. (2002), Las sombras del mañana. La dimensión subjetiva de la política, LOM Ediciones, Santiago.

McAdam, D.; Tarrow, S. \& Tilly, C. (2004), Dynamics of Contention, Cambridge University Press, Cambridge.

PNUD. (2002), Informe de Desarrollo Humano: Nosotros los chilenos, un desafío cultural. PNUD. Santiago.

Ruiz, C. (2007), “¿Qué hay detrás del malestar de la educación?”, Revista Análisis del Año 2006 .

Salazar, G. \& Pinto, J. (2002), Historia contemporánea de Chile (Vol. V, Niñez y juventud), LOM Ediciones, Santiago.

Tilly, C., \& Tarrow, S. (2007), Contentious politics, Paradigm Publishers, London.

Walder, A. (2009), "Political sociology and social movements”, Annual review of sociology, 393-412.

Yavuz, H. (2003), Islamic political identity in Turkey, Oxford University Press, Oxford.

Recibido: 24.01.2011

Aceptado: 03.03.2011 